\title{
Effectiveness of an "Exclusive Intervention Strategy" to increase medical male circumcision uptake among men aged 25- 49 years in South Africa
}

Jonathan M. Grund ${ }^{1 *}$ (D) Candice M. Chetty-Makkan², Sibuse Ginindza², Reuben Munyai², Helen Kisbey-Green², Mpho Maraisane $e^{2}$ and Salome Charalambous ${ }^{2,3}$

\begin{abstract}
Background: South Africa introduced medical male circumcision (MMC) to reduce HIV incidence. Mathematical modeling suggested that targeting MMC services to men aged 20-34 years could provide the most immediate impact on HIV incidence. However the majority of MMCs performed have been among males aged $\leq 25$ years. We evaluated an intervention package to increase MMC uptake among men aged 25-49 years.

Methods: We conducted a pre-post study to compare the proportion of men (aged 25-49 years) presenting for MMC during the formative (Phase 1) and intervention (Phase 2) phases in Ekurhuleni, Johannesburg, South Africa. The intervention included infrastructure changes that separated adults from adolescents at the MMC site, an exclusive men's health club, adult-specific demand generation materials, and discussions with community members. Results: Overall 2817 enrolled in the study with 1601 from Phase 1 and 1216 in Phase 2. A higher proportion of participants aged 25-49 years accessed MMC in Phase 2 compared to Phase 1 (59.4\% vs. 54.9\%; Prevalence Ratio = 1.08; 95\% Confidence Interval: 1.01-1.15; $p=0.019$ ). Participants with multiple partners in the past 12 months in Phase 2 were more likely to access MMC services compared to participants in Phase 1 (unadjusted Odds Ratio, 1.37; 95\% Cl:1.17-1.61; $p<0.001$ ). After adjusting for age, multiple partners remained a risk factor in Phase 2 (adjusted OR, 1.39; $95 \%$ Cl: $1.18-1.63 ; p<0.001)$.

Conclusions: The "Exclusive Intervention Strategy" was associated with a slight increase in the proportion of participants aged 25-49 years accessing MMC services, and an increase in those with HIV risk behaviors, during the intervention phase. These findings may provide important insights to overcoming barriers for accessing MMC services among men aged $25-49$ years.
\end{abstract}

Trial registration: The study is registered at ClinicalTrials.gov, number NCT02352961.

Keywords: Male circumcision, Demand creation, South Africa, HIV prevention

\footnotetext{
*Correspondence: jgrund@cdc.gov

${ }^{1}$ Centers for Disease Control and Prevention, 1600 Clifton Road NE, MS-E04,

Atlanta, GA 30333, USA

Full list of author information is available at the end of the article
}

(c) The Author(s). 2018 Open Access This article is distributed under the terms of the Creative Commons Attribution 4.0 International License (http://creativecommons.org/licenses/by/4.0/), which permits unrestricted use, distribution, and reproduction in any medium, provided you give appropriate credit to the original author(s) and the source, provide a link to the Creative Commons license, and indicate if changes were made. The Creative Commons Public Domain Dedication waiver (http://creativecommons.org/publicdomain/zero/1.0/) applies to the data made available in this article, unless otherwise stated. 


\section{Background}

Three randomized controlled trials confirmed that medical male circumcision (MMC) prevents HIV infection in men through heterosexual sex by at least $60 \%$ [1-4]. In 2007, the World Health Organization (WHO) and the Joint United Nations Programme on HIV/AIDS (UNAIDS) recommended male circumcision as a compelling HIV prevention intervention. Their recommendations specified that MMC should be offered in settings with low male circumcision coverage and high HIV prevalence [5]. Fourteen countries were determined to be prioritized for rapid MMC scale-up. It was estimated that providing 20.3 million MMCs among HIV-negative males aged 1549 years in the fourteen priority countries could avert 3.36 million new HIV infections and result in \$16.5 million in averted HIV treatment costs [6]. Working with Ministries of Health and MMC service delivery implementing partners, WHO estimates that nearly 12 million MMCs have been conducted through 2015 , and $61 \%$ of those are among males aged $\geq 15$ years [7].

South Africa is a priority country for MMC scale-up, as it has a national adult HIV prevalence of $17.9 \%$ [8] and has conducted approximately 1.86 million MMCs, which is $43 \%$ of their target of 4.3 million [7]. While the prevalence of male circumcision is estimated to be $54.0 \%$ nationally, there is high level of provincial variability [7]. The majority of MMCs performed among 15-49 year olds from 2010 to 2014 were in the provinces of KwaZulu-Natal, Gauteng, and Mpumalanga totaling more than 1.2 million [9]. WHO recommends MMC for males aged 15-49 years in the priority countries, but $65 \%$ of all MMCs supported by PEPFAR from 2010 to 2012 were among males aged 15-19 years. Similarly, South Africa has conducted almost 2 million MMCs for HIV prevention since 2009, though uptake has overwhelmingly attracted younger clients $[10,11]$.

Overall HIV prevalence in South Africa increases significantly with age: $0.7 \%$ of males aged $15-19$ years are HIV positive, and prevalence increases to $17.3 \%$ and 25.6 for males aged 25-29 and 30-34 years, respectively [11]. Studies have indicated that HIV risk behaviors also increase among older men in South Africa [11]. A total of $21.1 \%$ of black African males aged 25-49 years reported that they had more than one sexual partner in the past 12 months, compared with the national average of $12.6 \%$ among all races [11]. Condom use was also significantly lower among men aged $\geq 25$ years compared with younger males [11]. Modeling exercises have determined that in order for MMC to confer the most cost-effective and immediate impact on HIV incidence in South Africa, MMC for males aged 20-34 years must be prioritized and demand creation activities should specifically target these uncircumcised men, as MMC uptake remains low among this group [9].

Client-level barriers to MMC uptake among males aged $\geq 18$ years are well documented in qualitative research in several countries implementing MMC for HIV prevention. The most common barriers among men aged $\geq 20$ years include: shame at having to share waiting areas with younger MMC clients [12], confusion of MMC and traditional circumcision [13], concern that MMC is against cultural and ethnic identities [14], fear of pain and potential complications [13-15], difficulty in adhering to sexual abstinence for 6 weeks following MMC [13], and loss of income during the healing period $[15,16]$. Given the young age profile of MMC clients in South Africa, it is critical that demand creation activities address these client- and facility-level barriers in order to attract older men and maximize MMC's impact on HIV incidence.

This study reports the results from a novel recruitment strategy to increase MMC uptake among men aged 25-49 years at an MMC facility in Ekurhuleni, Gauteng Province, a district near Johannesburg, South Africa. A pre-post study design was conducted from April 2014-November 2015 at the Aurum Institute Winnie Mandela Male Sexual Health Clinic. This study assessed whether a targeted approach to demand creation could increase MMC uptake among men aged 2549 years with HIV risk behavior. The study's aim was to evaluate the effectiveness of an "Exclusive Intervention Strategy", comprised of customized MMC service delivery, to increase MMC uptake in men aged 25-49 years.

\section{Methods}

The study was conducted at a fixed clinic in a peri-urban area, where male health services including MMC are provided routinely. This implementation science study was embedded within the routine MMC service delivery program that included HIV testing services (HTS), registration for MMC, physical and genital examination, group counselling, one-on-one counselling (where separate informed consents were administered for the MMC procedure and for data to be used for research purposes), the MMC surgical procedure, post-operative observations, and discharge.

We obtained approval for the study from the Witwatersrand Human Research Ethics Committee, University of Witwatersrand (Approval Number: M130711) and the research committee of the Centers for Disease Control and Prevention (protocol number 6546). The study was registered on clinicaltrials.gov (NCT02352961). Voluntary written informed consent was obtained from all participants, and, in the case of illiterate participants, a 
thumbprint to acknowledge understanding in the presence of a witness was obtained.

The study consisted of two phases where Phase 1 and 2 took place in (1 April - 30 September 2014) and (22 June - 30 November 2015) respectively. For Phase 1, quantitative data was collected to determine the baseline estimate of risk factors for men (aged 18-49 years) who accessed routine MMC services. There was also a qualitative component where the barriers and motivators of MMC from male and female perspectives were explored to inform the intervention. Outcomes from the quantitative phase are reported here while the qualitative results are published elsewhere [17]. Interventions for Phase 2 were developed using the themes from the qualitative phase. Based on the qualitative findings and programmatic experiences, the intervention package included infrastructure changes at the MMC site that separated adults (aged $\geq 18$ years) from adolescents (10-17 years old), an exclusive men's health club (lounge area, free Wi-Fi access, VIP Facebook page by invite only, and shoe shine services) that was only available at the study clinic, adult-specific community demand generation material (billboards, pamphlets, posters and branded condoms) and "Imbizo" discussions with community members. "Imbizo" refers to traditional forums where elders discuss important issues with the community, and we used this concept to arrange broader discussions with men and women about MMC. The "Exclusive Intervention Strategy" was implemented only during Phase 2. The primary aim of Phase 2 was to determine if the "Exclusive Intervention Strategy" would increase the proportion of men (25-49 years) who accessed MMC services when compared to Phase 1.

Study recruitment for both phases targeted men (aged $\geq 18$ years) who were interested in MMC. Outreach teams distributed posters, pamphlets, branded condoms; held campaigns with the community; and used media such as advertising on taxis and trains to invite men to be circumcised. Men interested in MMC were given a clinic appointment. After registration, potential study participants were screened for study eligibility. Screening criteria included men who were interested in being circumcised, aged 18-49 years old, and able to communicate in English, IsiZulu, or Sepedi. Participants were given information about the study, and eligible men who were interested in participating provided written informed consent (Fig. 1). Demographic information (e.g. employment, financial and relationship status), sexual partner history, condom use, and the primary reasons for pursuing MMC from a set of multiple options were subsequently collected.

\section{Statistical analysis}

The statistical analysis was conducted using STATA (version 14, StataCorp LP, College Station, Texas). For the study data, the questionnaire extracts from Phase 1 and 2 were merged with the medical information that was recorded during the routine MMC procedures for the study sample. From the study data, we compared the proportion of men aged 25-49 years to all enrolled participants (18-49 years) between Phase 1 and 2 . Socio-demographic and sexual risk characteristics of men (18-49 years) at enrollment were described for Phase 1 and 2. A second data extract included all men who went through the routine MMC procedures (irrespective of study enrollment) and who consented for their routine data to be used for research. We analyzed the routine data in order to obtain the proportion of all men (aged 25-49 years) who accessed MMC services over the period overlapping with the study phases. For categorical variables (e.g. methods of recruitment), the frequencies and percentages are presented while the median and inter-quartile ranges are presented for continuous variables (e.g. participant age). The effect of study phase on the proportion of men (25-49 years) presenting for MMC was calculated using Fisher's Exact test and the prevalence ratio with a $95 \%$ confidence interval (CI). Univariate logistic regression, adjusting for age, was used to investigate the association of phase on sexual risk behaviors. Having more than one sexual partner in the last 12 months, partner greater than 5 years younger, no condom use during the last sex act, and having a sexually transmitted infection (STI) were the risk factors identified prior to analysis.

\section{Sample size}

It was assumed that approximately $40-55 \%$ of men ( $\geq 18$ years) who come to the facility for MMC would be within the target age range of 25-49 years with a variance of $2.5 \%$. The minimum number of men to be recruited was 1537 for a minimum power of $80 \%$ at $5 \%$ significance level.

\section{Results}

A total of 3836 men aged 18-49 years were screened: 2304 in Phase 1 and 1532 in Phase 2. Of those screened, a total of 2817 (73.4\%) enrolled in the study with 1601 in Phase 1 and 1216 in Phase 2. The enrolment to screening ratios for Phase 1 and Phase 2 were 69.5 and $79.4 \%$ respectively. The primary reason for screen failures in both phases was the inability to communicate in one of the study languages $(n=350)$. Of those enrolled, 2813 (99.9\%) were included in the analysis of the primary outcome with 1597 (56.8\%) from Phase 1 and 1216 (43.2\%) from Phase 2 (Fig. 1).

In Phase 1, the median age was 25 years, $28.7 \%$ had more than one sexual partner, $24.6 \%$ had a 


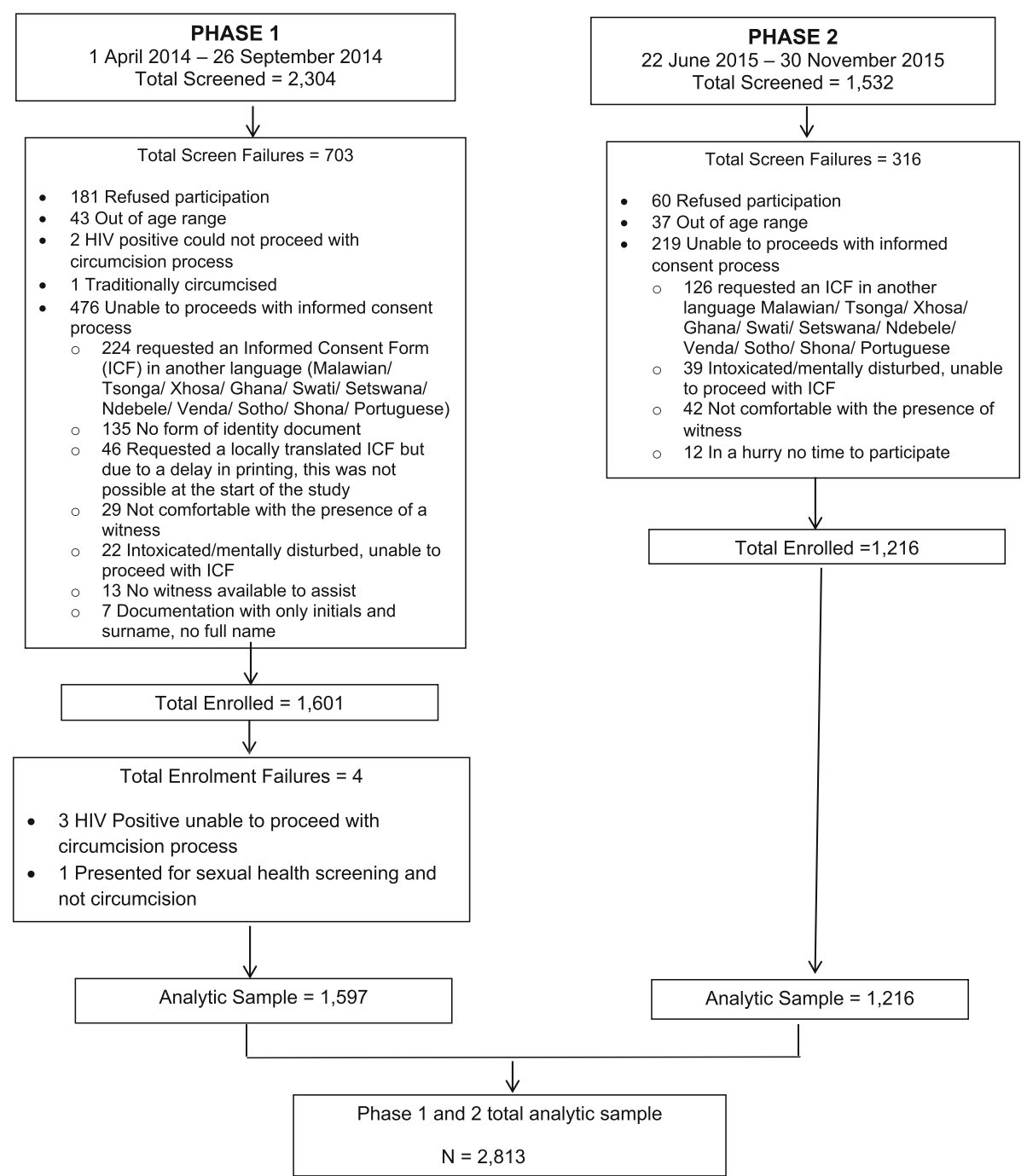

Fig. 1 Flow of enrolment diagram for Phase 1 and Phase 2 of the Imbizo study

sexual partner $>5$ years younger, $47.8 \%$ did not use a condom at last sex, and $2.8 \%$ were treated for an STI in the past 6 months. In addition, $44.6 \%$ were employed and $61.5 \%$ considered themselves as financially secure as their peers. In Phase 2, the median age was 26 years, $35.6 \%$ had more than one sexual partner, $27.2 \%$ had a sexual partner $>5$ years younger, $49.8 \%$ did not use a condom at last sex, and $2.9 \%$ were treated for an STI in the past 6 months. Additionally, $46.1 \%$ were employed and $64.8 \%$ considered themselves as financially secure as their peers (Table 1).

From the study data, a higher proportion participants aged 25-49 years accessed MMC services in Phase 2 when compared to Phase 1 ( $59.4 \%$ vs. $54.9 \%$; $\mathrm{PR}=1.08$; 95\% CI: $1.01-1.15 ; p=0.019$, Table 2). The proportion of men who were circumcised from the routinely collected data also showed that a higher proportion 25-
49 year olds accessed MMC services $(56.8 \%$ vs. $53.2 \%$; PR 1.07; 95\% CI: 1.04-1.10; $p<0.001$ ). When comparisons were done to assess MMC uptake during overlapping months of Phase 1 and 2 (23 June - 30 September), the proportion of participants aged 25-49 years were greater in Phase 2 vs. Phase 1 (57.8\% vs. 52.8\%; PR = 1.10; 95\% CI: $1.01-1.19 ; p=0.032$ ) (data not shown). Although there was an overall increase in the proportion of men (25-49 years) who accessed MMC services in Phase 2, the proportion of the increase was not significant. In addition, more men aged 25-49 years were circumcised per day during Phase 1 compared to Phase 2 (Table 2). Phase 1 comprised of 182 days (April 1, 2014 - September 30, 2014), and 4874 men were circumcised during this period. Phase 2 comprised of 161 days (June 22, 2015 - November 30, 2015), and 2750 men received MMC. The crude rates per calendar day is 26.8 men in Phase 1 and 17.1 men in Phase 2. 
Table 1 Participant demographic characteristics and sexual risk behaviours from Phase 1 and 2 of the Imbizo study

\begin{tabular}{|c|c|c|c|}
\hline Variable & Categories & $\begin{array}{l}\text { Phase } 1 \\
N=1597 \\
n(\%)\end{array}$ & $\begin{array}{l}\text { Phase } 2 \\
N=1216 \\
n(\%)\end{array}$ \\
\hline \multicolumn{4}{|l|}{ DEMOGRAPHICS } \\
\hline Age (in years) & Median (IQR) & $25(21-30)$ & $26(21-32)$ \\
\hline \multirow[t]{6}{*}{ Employment Status } & Unemployed & $484(30.3)$ & $291(23.9)$ \\
\hline & Employed & $712(44.6)$ & $560(46.1)$ \\
\hline & Student & $282(17.7)$ & $257(21.1)$ \\
\hline & Self-Employed & $96(6.0)$ & $91(7.5)$ \\
\hline & Other & $12(0.8)$ & $16(1.3)$ \\
\hline & Missing & $11(0.7)$ & $1(0.08)$ \\
\hline \multirow[t]{5}{*}{ Family Finances } & Not enough food/clothes & $158(9.9)$ & $149(12.3)$ \\
\hline & Enough food/clothes but short on other & $689(43.1)$ & $474(39.0)$ \\
\hline & Basics but not enough for expensive things & $702(44.0)$ & $541(44.5)$ \\
\hline & Enough to save or buy expensive things & $47(2.9)$ & $48(3.9)$ \\
\hline & Missing & $1(0.06)$ & $4(0.3)$ \\
\hline \multirow[t]{4}{*}{ Peer Financial Comparison } & Poorer than others & $389(24.4)$ & $262(21.5)$ \\
\hline & About the same as others & $982(61.5)$ & $788(64.8)$ \\
\hline & Better off than others & $217(13.6)$ & $160(13.2)$ \\
\hline & Missing & $9(0.6)$ & $6(0.5)$ \\
\hline \multicolumn{4}{|l|}{ RELATIONSHIP HISTORY AND SEXUAL RISK BEHAVIOUR } \\
\hline \multirow[t]{3}{*}{ Relationship Status in the last 12 months } & No partner or one steady/casual partner at same given time & $1136(71.1)$ & $781(64.2)$ \\
\hline & $>1$ partner at same given time & $459(28.7)$ & $433(35.6)$ \\
\hline & Missing & $2(0.1)$ & $2(0.2)$ \\
\hline \multirow[t]{4}{*}{ Live-in partners in the last 12 months } & No & $917(57.4)$ & $695(57.2)$ \\
\hline & Yes & $538(33.7)$ & $433(35.6)$ \\
\hline & Not applicable-no partners in the last year & $141(8.8)$ & $86(7.1)$ \\
\hline & Missing & $1(0.06)$ & $2(0.2)$ \\
\hline \multirow{5}{*}{$\begin{array}{l}\text { How many partners did you have in the } \\
\text { last } 6 \text { months? }\end{array}$} & None & $216(13.5)$ & $182(15.0)$ \\
\hline & One & $874(54.7)$ & $573(47.1)$ \\
\hline & Two & $285(17.8)$ & $233(19.2)$ \\
\hline & More than two & $189(11.8)$ & $124(10.2)$ \\
\hline & Missing & $33(2.1)$ & $104(8.6)$ \\
\hline \multirow{5}{*}{$\begin{array}{l}\text { In the last } 6 \text { months how often have you } \\
\text { used a condom? }\end{array}$} & Never & $504(31.6)$ & $328(27.0)$ \\
\hline & Sometimes & $552(34.6)$ & $371(30.5)$ \\
\hline & Most times & $84(5.3)$ & $86(7.1)$ \\
\hline & Every time & $376(23.5)$ & $249(20.5)$ \\
\hline & Missing & $81(5.1)$ & $182(15.0)$ \\
\hline \multirow[t]{4}{*}{ How old was your last sexual partner? } & About same age or $>5$ years older & $1159(72.6)$ & $824(67.8)$ \\
\hline & $>5$ years younger & $393(24.6)$ & $331(27.2)$ \\
\hline & Not applicable-never had sex & $40(2.5)$ & $56(4.6)$ \\
\hline & Missing & $5(0.3)$ & $5(0.4)$ \\
\hline \multirow[t]{4}{*}{ Did you use a condom the last time you had sex? } & No & $763(47.8)$ & $606(49.8)$ \\
\hline & Yes & $789(49.4)$ & $550(45.2)$ \\
\hline & Not applicable-never had sex & $42(2.6)$ & $56(4.6)$ \\
\hline & Missing & $3(0.2)$ & $4(0.3)$ \\
\hline
\end{tabular}


Table 1 Participant demographic characteristics and sexual risk behaviours from Phase 1 and 2 of the Imbizo study (Continued)

\begin{tabular}{|c|c|c|c|}
\hline Variable & Categories & $\begin{array}{l}\text { Phase } 1 \\
N=1597 \\
\mathrm{n}(\%)\end{array}$ & $\begin{array}{l}\text { Phase } 2 \\
N=1216 \\
\mathrm{n}(\%)\end{array}$ \\
\hline \multirow[t]{5}{*}{ Suspect last partner of infidelity } & No & $773(48.4)$ & $513(42.2)$ \\
\hline & Yes & $368(23.0)$ & $280(23.0)$ \\
\hline & Not sure & $409(25.6)$ & $364(29.9)$ \\
\hline & Not applicable-never had sex & $40(2.5)$ & $56(4.6)$ \\
\hline & Missing & $7(0.4)$ & $3(0.2)$ \\
\hline \multicolumn{4}{|l|}{ SUBSTANCE USE HISTORY } \\
\hline \multirow[t]{4}{*}{ Spent time in a tavern in the last 12 months } & Never & $751(47.0)$ & $557(45.8)$ \\
\hline & Occasionally & $606(37.9)$ & $486(40.0)$ \\
\hline & Frequently & $240(15.0)$ & $170(14.0)$ \\
\hline & Missing & $0(0)$ & $3(0.2)$ \\
\hline \multirow[t]{4}{*}{ Drank alcohol in the last 12 months } & Never & $586(36.7)$ & $401(33.0)$ \\
\hline & Occasionally & $739(46.3)$ & $597(49.1)$ \\
\hline & Frequently & $272(17.0)$ & $216(17.8)$ \\
\hline & Missing & $0(0)$ & $2(0.2)$ \\
\hline \multicolumn{4}{|l|}{ SEXUALLY TRANSMITTED INFECTIONS } \\
\hline \multirow[t]{3}{*}{ Have you been treated for STIs past 6 months } & No & 1531 (95.9) & 1092 (89.8) \\
\hline & Yes & $45(2.8)$ & $35(2.9)$ \\
\hline & Missing & $21(1.3)$ & $89(7.3)$ \\
\hline \multirow{3}{*}{$\begin{array}{l}\text { Current treatable STI as diagnosed by clinical staff } \\
\text { member }\end{array}$} & No & $1538(96.3)$ & 1099 (90.4) \\
\hline & Yes & $30(1.9)$ & $20(1.6)$ \\
\hline & Missing & $29(1.8)$ & $97(8.0)$ \\
\hline
\end{tabular}

Figure 2 shows the monthly results of participants presenting for MMC. In both phases, the highest number of participants presented during July (762) and August (557). During these months in Phase 1, the majority of participants were aged 25-49 years, whereas younger clients were more common during the other months. For Phase 2, the age distribution for participants presenting for MMC is similar to Phase 1 but more pronounced in August and September, as 68.6 and $73.5 \%$ of clients were aged 25-49 years respectively.
The association of study phase on sexual risk behaviors showed that participants from Phase 2 with multiple partners during the same or at different times over the past 12 months were more likely to access MMC services when compared to Phase 1 (unadjusted OR, 1.37; 95\% CI:1.17-1.61; $p<0.001)$. After adjusting for age, multiple partners remained as a risk factor in Phase 2 (adjusted OR, 1.39; 95\% CI: 1.18$1.63 ; p<0.001$ ). The other HIV risk behaviors (having a sexual partner who was greater than 5 years

Table 2 Proportion and number of circumcised clients in different age-groups, by study dates and routine MMC services of the Imbizo study

\begin{tabular}{|c|c|c|c|c|c|}
\hline \multicolumn{6}{|l|}{ IMBIZO RESEARCH STUDY } \\
\hline \multirow[t]{2}{*}{ Study Phase (recruitment dates) } & & \multirow[t]{2}{*}{$18-24$ years } & \multirow[t]{2}{*}{$25-49$ years } & \multicolumn{2}{|c|}{ Prevalence Ratio comparing Phase 2 to Phase 1 (25-49 years) } \\
\hline & & & & PR $(95 \% \mathrm{Cl})$ & $p$-value \\
\hline Phase 1 (01 Apr 2014-30 Sep 2014) N = 1597 & n (\%) & $720(45.1)$ & $877(54.9)$ & 1 & 0.019 \\
\hline Phase 2 (22 Jun -30 Nov 2015) N=1216 & n (\%) & $494(40.6)$ & $722(59.4)$ & $1.08(1.01-1.15)$ & \\
\hline \multicolumn{6}{|l|}{ MMC ROUTINE DATA } \\
\hline \multicolumn{2}{|c|}{ Routine data (dates coinciding with Phase recruitment) } & 18-24 years & $25-49$ years & \multicolumn{2}{|c|}{ Prevalence Ratio comparing Phase 2 to Phase 1 (25-49 years) } \\
\hline Phase 1 (01 Apr 2014-30 Sep 2014) N = 9169 & n (\%) & $4295(46.8)$ & $4874(53.2)$ & 1 & $<0.001$ \\
\hline Phase 2 (22 Jun 2015-30 Nov 2015) $N=4839$ & n (\%) & $2089(43.2)$ & $2750(56.8)$ & $1.07(1.04-1.10)$ & \\
\hline
\end{tabular}




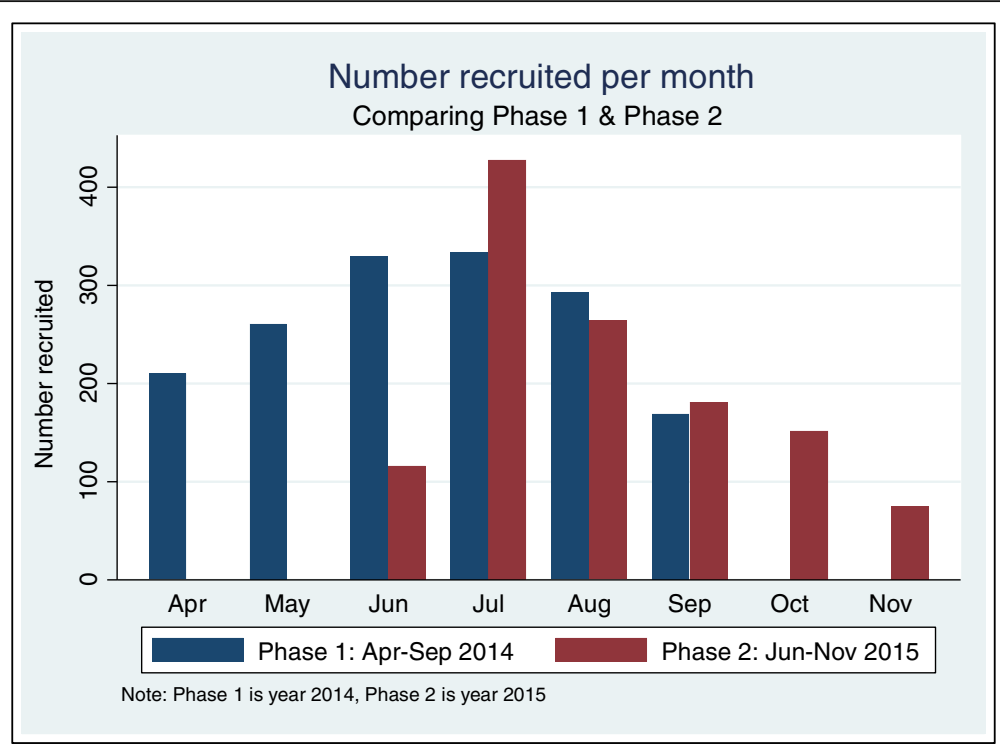

Fig. 2 Number of MMC clients recruited per month for Phase 1 (April-September 2014) \& Phase 2 (June-November 2015)

younger, not using a condom use at last sex, and reported STIs in the past 6 months) were not associated with the study phases (Table 3).

Participants from both study phases also reported primary reasons for attending the MMC clinic. Media, which included Facebook, billboards, flyers, and all other promotional materials that were part of the intervention, was the highest ranked reason at $20.3 \%$. Hygiene was the second highest ranked reason at $17.9 \%$, followed by recommendations from other clients or relatives who underwent MMC (17.1 and $13.6 \%$ respectively), and recommendations from partners $(11.0 \%)$.

\section{Discussion}

Our study showed that an "Exclusive Intervention Strategy", which included infrastructure improvements, outreach branded materials, access to a VIP Facebook page, invitations to community discussion groups, and special services in an exclusive men's lounge, slightly increased the proportion of participants aged 25-49 years who accessed MMC services. The "Exclusive Intervention Strategy" may provide important insights to overcoming barriers for accessing MMC services among men aged 25-49 years and creates an opportunity to identify men at high risk of HIV who could be targeted for future HIV prevention interventions.

Table 3 Logistic regression investigating the association of sexual risk behaviours for Phase 1 and Phase 2

\begin{tabular}{|c|c|c|c|c|c|c|c|c|}
\hline & \multicolumn{2}{|c|}{ Relationship Status in the last 12 months $^{a}$} & \multicolumn{2}{|c|}{$\begin{array}{l}\text { Age of last sexual } \\
\text { partner }^{\mathrm{b}}\end{array}$} & \multicolumn{2}{|c|}{$\begin{array}{l}\text { Used a condom } \\
\text { the last sex act }\end{array}$} & \multicolumn{2}{|c|}{$\begin{array}{l}\text { Report of any STIs in the past } \\
6 \text { months }{ }^{d}\end{array}$} \\
\hline & $\begin{array}{l}\text { No partner or one steady/ } \\
\text { casual partner at any } \\
\text { given time }\end{array}$ & $\begin{array}{l}\text { > One partner at } \\
\text { some given time } \\
\text { (1) }\end{array}$ & $\begin{array}{l}\text { About same } \\
\text { or }>5 \text { years } \\
\text { older }\end{array}$ & $\begin{array}{l}>5 \text { years } \\
\text { younger } \\
(1)\end{array}$ & Yes & $\begin{array}{l}\text { No } \\
(1)\end{array}$ & $\begin{array}{l}\text { Had an STI in } \\
\text { the past } \\
6 \text { months }\end{array}$ & $\begin{array}{l}\text { No STI in the } \\
\text { past } 6 \text { months } \\
\text { (1) }\end{array}$ \\
\hline $\begin{array}{l}\text { Phase } 1 \text { (23 Jun -30 Sep } \\
\text { 2014) } N=1597\end{array}$ & $1136(71.1)$ & $459(28.7)$ & $1159(72.6)$ & $\begin{array}{l}393 \\
(24.6)\end{array}$ & $\begin{array}{l}789 \\
(49.4)\end{array}$ & $\begin{array}{l}763 \\
(47.8)\end{array}$ & $1531(95.9)$ & $45(2.8)$ \\
\hline $\begin{array}{l}\text { Phase } 2 \text { (22 Jun -30 Sep } \\
\text { 2015) } N=1216\end{array}$ & $781(64.2)$ & $433(35.6)$ & $824(67.8)$ & $\begin{array}{l}331 \\
(27.2)\end{array}$ & $\begin{array}{l}550 \\
(45.2)\end{array}$ & $\begin{array}{l}606 \\
(49.8)\end{array}$ & $1092(89.8)$ & $35(2.9)$ \\
\hline $\begin{array}{l}\text { Unadjusted OR }(95 \% \mathrm{Cl}) \\
\text { Phase } 2 \text { to Phase 1, } p^{-} \\
\text {value }\end{array}$ & \multicolumn{2}{|l|}{$1.37(1.17 ; 1.61), p<0.001$} & \multicolumn{2}{|c|}{$\begin{array}{l}1.18(1.00 ; 1.41) \\
p=0.05\end{array}$} & \multicolumn{2}{|c|}{$\begin{array}{l}1.14(0.98 ; 1.33) \\
p=0.09\end{array}$} & \multicolumn{2}{|c|}{$1.09(0.70 ; 1.71), p=0.71$} \\
\hline $\begin{array}{l}\text { Adjusted for age } \mathrm{e} \text { OR }(95 \% \\
\text { Cl) Phase } 2 \text { to Phase } 1, p^{-} \\
\text {value }\end{array}$ & \multicolumn{2}{|l|}{$1.39(1.18 ; 1.63), p<0.001$} & \multicolumn{2}{|c|}{$\begin{array}{l}1.02(0.85 ; 1.24) \\
p=0.81\end{array}$} & \multicolumn{2}{|c|}{$\begin{array}{l}1.06(0.91 ; 1.25) \\
p=0.42\end{array}$} & \multicolumn{2}{|c|}{$1.09(0.69 ; 1.71), p=0.71$} \\
\hline
\end{tabular}

atwo missing relationship status in each phase

${ }^{\mathrm{b}} 42$ not sexually active in the past 12 months in Phase 1,56 not sexually active in the past 12 and 5 missing in Phase 2

' 42 not sexually active in the past 12 months, 2 did not know partner's age and 1 missing in Phase 1.56 not sexually active in the past 12 months in Phase 2,2 did not know, I, 4 missing in Phase 2

d 110 excluded in the analysis because of missing data (21 Phase 1, 89 Phase 2)

${ }^{\mathrm{e}}$ Adjusted for age in four categories; $18-20$ years, 21-24 years, 25-30 years, 31-49 years 
Participants in the intervention phase were older (median age 26 vs. 25 years), more likely to be employed (46.1 vs $44.6 \%)$, and more financially secure (64.8\% vs. $61.5 \%)$. In addition, men with greater risk behaviors were more likely to come for MMC in Phase 2 over Phase 1: participants with multiple concurrent partners (35.6\% vs. $28.7 \%)$, no condom use at last sex (49.8\% vs. $47.8 \%)$, and overall time spent in a tavern (53.8\% vs. $52.9 \%)$.

However, routinely collected site-level data suggest that greater proportions of 25-49 year olds were coming to the MMC site (56.8\% vs. $53.2 \%$ ), though to a lesser extent than among study participants. The increases in men aged 25-49 years coming to the MMC site could be attributed to the targeted messaging that was designed to appeal to men aged 25-49 years during the intervention phase, but it could also be that some clients aged 18-25 years were attracted to the targeted messages. It is also possible that more "older" men were interested in pursuing MMC during the winter months, as seasonality is a strong predictor of MMC uptake in South Africa. July and August include school holidays, which could suggest that the separation of clients by age is a facilitator for men aged $\geq 25$ years. Also, it is possible that the lower crude rate of men aged 25-49 getting MMC per day is lower in Phase 2 vs. Phase 1 is due to increasing saturation of $\mathrm{MMC}$ in the communities close to the study site in Ekurhuleni.

Our study adds to growing research from sub-Saharan Africa about MMC and demand creation to encourage hard-to-reach men to pursue MMC. Thirumurthy et al. (2014) offered economic incentives to men aged 2549 years in Nyanza region, Kenya on the condition that they were circumcised within 2 months at one of the nine MMC study sites. Study groups included participants who received food vouchers worth $\sim \$ 2.50, \sim \$ 8.75$, and $\sim \$ 15.00$ and no compensation (control). MMC uptake was strongest in the groups that received $\sim \$ 8.75$ and $~ \$ 15.00$ (AOR 4.3; 95\% CI, 1.7-10.7 and AOR 6.2; 95\% CI, 2.6-15.0) [18]. In Tanzania, Wambura et al. targeted demand creation messaging, MMC site-level alterations, and engagement of female sexual partners was investigated to increase uptake in men 20-34 years. The study had a strong effect in Tabora region (Risk Ratio = 2.39, 95\% CI 1.7-3.4) but no significant effect in Njombe region ( $\mathrm{RR}=0.77$; 95\%CI 0.4-1.6) [19]. In South Africa, Wilson et al. conducted a randomized controlled trial with men aged $\geq 18$ years in Soweto. The intervention arms included participants receiving $\sim \$ 10.00$, additional information about $\mathrm{MMC}$, or a "challenge" question to encourage participants to come for MMC. The compensation and "challenge" question arms resulted in significantly higher MMC uptake [OR 5.30 (95\% CI, 2.2012.76) and 2.70 (CI, 1.05-6.91, respectively [20]. Also in South Africa, Auvert et al. offered uncircumcised men home-based motivational interviews that addressed common barriers to MMC [21]. For men opting for circumcision, they received financial compensation for lost work time. This study resulted in a relative increase of MMC prevalence of $43.6 \%$.

Our findings are aligned with other MMC demand creation studies to increase MMC uptake in sub-Saharan Africa. The studies with the largest effect sizes are those that offered financial compensation, which suggests that the costs associated with travel to the MMC clinic and time taken off from work during recovery from MMC surgery might be substantial barriers preventing some men from pursuing MMC $[18,20]$. However offering financial compensation along with $\mathrm{MMC}$ is challenging to implement on a large scale, and the additional program costs may result in higher unit costs. The Tanzanian study's overall results were more modest and similar to ours, which may suggest that additional research should include enhanced demand creation, clinic modifications, and some financial incentives to appeal to potential clients with varied barriers [19].

Our study had several strengths and limitations. The strength of our study is that the intervention package was informed by qualitative research that incorporated user preferences with common cultural practices to appeal to the community. The intervention package addressed barriers that prevented "older" men from coming for $\mathrm{MMC}$, including queuing with adolescent clients, and it appealed to men's interest in having an "exclusive" experience at a men's health clinic, including shoe shine services, lounge access, etc. The study's limitations included the study design that involved different populations in Phases 1 and 2 who could have had different reasons for coming for MMC. The study site was also a large, peri-urban men's health clinic, so generalizing these results might be challenging for rural health facilities that might experience challenges separating services or establishing an exclusive lounge area. In addition, MMC is a well-known health intervention among males in Gauteng Province, South Africa, so the intervention may need to be altered depending on MMC coverage in another population. Finally, the study instruments did not allow for a factor analysis to attribute specific components of the intervention that were most responsible for the increase in MMC uptake among men aged 25-49 years.

\section{Conclusion}

Our study showed that a targeted demand creation strategy that separated adolescent and adult men and offered "exclusive" services to men aged 25-49 years slightly increased the proportion of clients aged 25-49 years getting $M M C$ at a study facility in South Africa. The components of this intervention package should inform novel demand creation strategies to recruit older and 
higher risk men to MMC for HIV prevention services. Future demand creation studies should assess and incorporate client-level preferences to increase impact.

\section{Abbreviations}

Cl: Confidence Interval; HIV: Human Immunodeficiency Virus; HTS: HIV Testing Services; IQR: Interquartile Range; MMC: Medical Male Circumcision; OR: Odds Ratio; PR: Prevalence Ratio; RR: Risk Ratio; STI: Sexually Transmitted Infection UNAIDS: Joint United Nations Programme on HIV/AIDS; VIP: Very Important Person; WHO: World Health Organization

\section{Acknowledgements}

The authors would like to thank all of the participants for taking the time to take part in this study. We would also like to thank all of the staff at The Aurum Institute Winnie Mandela Male Sexual Health Clinic for ensuring successful implementation of the study. Special thanks to the Imbizo research team, Michael Kgampe (Clinic Manager), Sister Nozipho Makuwerere (Assistant Clinic Manager), Mmathabo Rangoshe (Community Engagement Manager) and the following clinicians Dr. Vusi Molapisi, Dr. Tozama Makanda and Dr. Nkosingiphile Kemini.

\section{Funding}

This research has been supported by the President's Emergency Plan for AIDS Relief (PEPFAR) through the Centers for Disease Control and Prevention (CDC) under the terms of the Cooperative Agreement Number $5 \cup 01 \mathrm{GH} 00522$. The findings and conclusions in this manuscript are those of the authors and do not necessarily represent the official position of the funding agencies.

\section{Availability of data and materials}

The datasets analyzed during the current study are available from the corresponding author on reasonable request.

\section{Authors' contributions}

JMG, CMCM, MM, HKG, and SC contributed to the study design. JMG, RM, CMCM, HKG, MM, and SC oversaw study implementation. RM and CMCM oversaw the formative research. RM and CMCM managed the data collection. SG did the data analysis. JMG, CMCM, and SC wrote the first draft of the manuscript. All authors were involved in approving the final draft, agree to be accountable for the work, and have read and approved the final manuscript.

\section{Ethics approval and consent to participate}

We obtained approval for the study from the Witwatersrand Human Research Ethics Committee, University of Witwatersrand (Approval Number: M130711) and the research committee of the Centers for Disease Control and Prevention (protocol number 6546). The study was registered on clinicaltrials.gov (NCT02352961). Voluntary written informed consent was obtained from all participants, and, in the case of illiterate participants, a thumbprint to acknowledge understanding in the presence of a witness was obtained.

\section{Consent for publication}

Not applicable.

\section{Competing interests}

The authors declare that they have no competing interests.

The funder of the study participated in the study design, data interpretation, and writing of the report. The corresponding author had full access to all the data in the study and had final responsibility for the decision to submit for publication.

\section{Publisher's Note}

Springer Nature remains neutral with regard to jurisdictional claims in published maps and institutional affiliations.

\section{Author details}

Centers for Disease Control and Prevention, 1600 Clifton Road NE, MS-E04, Atlanta, GA 30333, USA. ${ }^{2}$ The Aurum Institute, Johannesburg, Gauteng
Province, South Africa. ${ }^{3}$ The School of Public Health, University of the Witwatersrand, Johannesburg, South Africa.

Received: 29 August 2017 Accepted: 20 June 2018 Published online: 13 July 2018

\section{References}

1. Auvert B, Taljaard D, Lagarde E, et al. Randomized, controlled intervention trial of male circumcision for reduction of HIV infection risk: the ANRS 1265 trial. PLoS Med. 2005:e298.

2. Bailey RC, Moses S, Parker CB, et al. Male circumcision for HIV prevention in young men in Kisumu, Kenya: a randomised controlled trial. Lancet. 2007; 369(9562):643-56.

3. Gray RH, Kigozi K, Serwadda D, et al. Male circumcision for HIV prevention in men in Rakai, Uganda: a randomised trial. Lancet. 2007;369(9562):657-66.

4. Weiss HA, Quigley MA, Hayes RJ. Male circumcision and risk of HIV infection in sub-Saharan Africa: a systematic review and meta-analysis. AIDS. 2000;14: 2361-70.

5. WHO and UNAIDS, New Data on Male Circumcision and HIV Prevention: Policy and Program Implications. WHO/UNAIDS Technical Consultation on Male Circumcision and HIV Prevention: Research Implications for Policy and Programming 2007: Montreux, Switzerland. http://data.unaids.org/pub/ report/2007/mc_recommendations_en.pdf. Accessed 10 June 2018.

6. Njeuhmeli E, Forsythe $S$, Reed J, et al. Voluntary medical male circumcision: modeling the impact and cost of expanding male circumcision for HIV prevention in eastern and southern Africa. PLoS Med. 2011:8(11): e1001132.

7. WHO. Voluntary Medical Male Circumcision for HIV Prevention in 14 Priority Countries in East and Southern Africa. June 2016. WHO Progress Brief. http:// apps.who.int/iris/bitstream/10665/246174/1/WHO-HIV-2016.14-eng.pdf?ua=1. Accessed 10 June 2018

8. WHO/UNAIDS Global Report: UNAIDS report on the global AIDS epidemic 2013. http://www.unaids.org/sites/default/files/en/media/unaids/ contentassets/documents/epidemiology/2013/gr2013/UNAIDS_Global_ Report 2013 en.pdf. Accessed 10 June 2018.

9. Kripke K, Chen P-A, Vazzano A, et al. Cost and impact of voluntary medical male circumcision in South Africa: focusing the program on specific age groups and provinces. PLoS One. 2016;11(7):e0157071. https://doi.org/10. 1371/journal.pone.0157071. Accessed 10 June 2018.

10. Centers for Disease Control and Prevention. Voluntary Medical Male Circumcision - Southern and Eastern Africa, 2010-2012. MMWR. 2013; 62(47):953-7.

11. Shisana O, Rehle T, Simbayi LC, et al. South African National HIV Prevalence, Incidence and Behaviour Survey, 2012. Cape Town: HSRC Press; 2014.

12. Plotkin M, Castor D, Mziray H, et al. "Man, what took you so long?" social and individual factors affecting adult attendance at voluntary medical male circumcision services in Tanzania. Glob Health Sci Pract. 2013;1(1):108-16. https://doi.org/10.9745/GHSP-D-12-00037. Accessed 10 June 2018.

13. Khumalo-Sakutukwa G, Lane $\mathrm{T}$, van-Rooyen $\mathrm{H}$, et al. Understanding and addressing socio-cultural barriers to medical male circumcision in traditionally non-circumcising rural communities in sub-Saharan Africa. Cult Health Sex. 2013:15(9):1085-100.

14. Westercamp N, Bailey RC. Acceptability of male circumcision for prevention of HIV/AIDS in sub-Saharan Africa: a review. AIDS Behav. 2007:11(3):341-55.

15. Evens $E$, Lanham $M$, Hart $C$, et al. Identifying and addressing barriers to uptake of voluntary medical male circumcision in Nyanza, Kenya among men 18-35: a qualitative study. PLoS One. 2014;9(6):e98221. https://doi.org/ 10.1371/journal.pone.0098221. Accessed 10 June 2018.

16. Herman-Roloff A, Llewellyn E, Obiero W, et al. Implementing voluntary medical male circumcision for HIV prevention in Nyanza Province, Kenya: lessons learned during the first year. PLoS One. 2014;6(4):e18299. https://doi. org/10.1371/journal.pone.0018299. Accessed 10 June 2018.

17. Chetty-Makkan CM, JM Grund, R Munyai, et al. "Describing the role of women in promoting medical male circumcision to adult men (25-49 years) in a peri-urban clinic of South Africa". Poster Presentation A-792-029703849 at the International AIDS Conference, Durban. 2016. http:// programme.aids2016.org/Abstract/Abstract/3849. Accessed 10 June 2018.

18. Thirumurthy $\mathrm{H}$, Masters $\mathrm{SH}$, Rao S, et al. Effect of providing conditional economic compensation on uptake of voluntary medical male circumcision in Kenya: a randomized clinical trial. JAMA. 2014;312(7):703-11. 
19. Wambura M, Mahler H, Grund JM, et al. Increasing voluntary medical male circumcision uptake among adult men in Tanzania. AIDS. 2017;31:1025-34.

20. Wilson N, Frade $S$, Rech D, et al. Advertising for demand creation for voluntary medical male circumcision. JAIDS. 2016;72:S293-6.

21. Marshall, E, Rain-Taljaard, R, Tsepe M, et al. Obtaining a male circumcision prevalence rate of $80 \%$ among adults in a short time. Medicine, 2017. vol:96 iss:4 pg:e5328

Ready to submit your research? Choose BMC and benefit from:

- fast, convenient online submission

- thorough peer review by experienced researchers in your field

- rapid publication on acceptance

- support for research data, including large and complex data types

- gold Open Access which fosters wider collaboration and increased citations

- maximum visibility for your research: over $100 \mathrm{M}$ website views per year 